\title{
Relationship between sclerostin and cardiovascular calcification in hemodialysis patients: a cross-sectional study
}

Vincent M Brandenburg ${ }^{1 * \dagger}$, Rafael Kramann ${ }^{2 \dagger}$, Ralf Koos ${ }^{1}$, Thilo Krüger ${ }^{2}$, Leon Schurgers ${ }^{3}$, Georg Mühlenbruch ${ }^{4}$, Sinah Hübner ${ }^{2}$, Ulrich Gladziwa ${ }^{5}$, Christiane Drechsler ${ }^{6}$ and Markus Ketteler ${ }^{7}$

\begin{abstract}
Background: Sclerostin is a Wnt pathway antagonist regulating osteoblast activity and bone turnover. Here, we assessed the potential association of sclerostin with the development of coronary artery (CAC) and aortic valve calcifications (AVC) in haemodialysis (HD) patients.

Methods: We conducted a cross-sectional multi-slice computed tomography (MS-CT) scanning study in 67 chronic HD patients (59.4 $\pm 14.8 \mathrm{yrs}$ ) for measurement of CAC and AVC. We tested established biomarkers as well as serum sclerostin (ELISA) regarding their association to the presence of calcification. Fifty-four adults without relevant renal disease served as controls for serum sclerostin levels. Additionally, sclerostin expression in explanted aortic valves from 15 dialysis patients was analysed ex vivo by immunohistochemistry and mRNA quantification (Qt-RT-PCR).

Results: CAC (Agatston score > 100) and any AVC were present in $65 \%$ and in $40 \%$ of the MS-CT patient group, respectively. Serum sclerostin levels $(1.53 \pm 0.81$ vs $0.76 \pm 0.31 \mathrm{ng} / \mathrm{mL}, p<0.001)$ were significantly elevated in HD compared to controls and more so in HD patients with AVC versus those without AVC (1.78 \pm 0.84 vs $1.35 \pm$ $0.73 \mathrm{ng} / \mathrm{mL}, \mathrm{p}=0.02$ ). Multivariable regression analysis for AVC revealed significant associations with higher serum sclerostin. Ex vivo analysis of uraemic calcified aortic valves $(n=10)$ revealed a strong sclerostin expression very close to calcified regions (no sclerostin staining in non-calcified valves). Correspondingly, we observed a highly significant upregulation of sclerostin mRNA in calcified valves compared to non-calcified control valves.
\end{abstract}

Conclusion: We found a strong association of sclerostin with calcifying aortic heart valve disease in haemodialysis patients. Sclerostin is locally produced in aortic valve tissue adjacent to areas of calcification.

Keywords: Aortic valve disease, Cardiovascular disease, Coronary calcification, Hemodialysis, Mineral metabolism, Vascular calcification, Renal osteodystrophy, Sclerostin

\section{Background}

The majority of long-term haemodialysis (HD) patients are affected by cardiovascular calcification (CVC) [1,2]. $\mathrm{CVC}$ constitutes one of the driving forces for the enormously elevated cardiovascular mortality in patients with CKD or end-stage renal disease (ESRD) $[3,4]$.

Numerous proteins have been identified to be significantly associated with the presence and amount of

\footnotetext{
* Correspondence: Vincent.Brandenburg@post.rwth-aachen.de

${ }^{\dagger}$ Equal contributors

'Department of Cardiology, University Hospital of the RWTH, Pauwelsstraße 30, D- 52057 Aachen, Germany

Full list of author information is available at the end of the article
}

uraemic CVC in the past (e.g. osteoprotegerin (OPG), alkaline phosphatase (AP), fetuin-A, matrix-gla protein (MGP), parathyroid hormone (PTH), C-reactive protein (CRP)) [4-8], some of which are also associated with morbidity and mortality in dialysis patients [9-11]. Several of these parameters are also involved in the regulation of bone metabolism and osseous calcification processes. Immunohistochemistry examinations of calcified cardiovascular structures showed that some of these "bone proteins" are deposited adjacent to calcification nidus indicating an osseous transdifferention of the vascular wall cells [12].

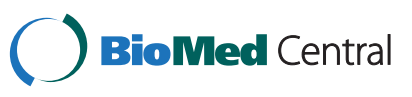


A novel candidate protein for this bone-vascular axis is sclerostin $(22.5 \mathrm{kDa})$, which is synthesized in osteocytes and is a potent down-regulator of bone metabolism by reducing osteoblast differentiation and function via canonical Wnt-signalling inhibition [13,14]. High serum sclerostin was described in patients with CKD [15]. Recent reports indicated that serum sclerostin levels may reflect reduced bone metabolism and may be useful as marker for low-turnover bone disease in ESRD patient [16]. Therefore, we hypothesized that sclerostin is also linked to vascular calcification in dialysis patients.

The aim of the present study was to assess whether CVC in haemodialysis patients is associated with levels of circulating sclerostin and whether valvular calcification goes along with local sclerostin production. We performed a cross-sectional study among HD patients who underwent MS-CT scanning for CAC and AVC assessment. Additionally, an ex vivo study with aortic valve tissue samples was performed in order to analyse local valvular sclerostin expression in calcified versus noncalcified aortic valve tissue.

\section{Methods}

\section{Patient characteristics}

Patients for MSCT calcification assessment were all chronic HD patients. Standard bicarbonate dialysis procedures were thrice weekly haemodialysis or haemodiafiltration sessions ( 4.5 to $5.5 \mathrm{hrs}$ ). Dialysate calcium concentration was 1.25 or $1.5 \mathrm{mmol} / \mathrm{L}$. All adult hemodialysis patients from the Aachen University Hospital and three collaborating dialysis centers were eligible after written and informed consent. Patients were not included in the study if they anticipated living kidney donation, had current atrial fibrillation, severe comorbidities, a history of coronary bypass surgery, coronary stent implantation or aortic valve surgery (patient characteristics Table 1) (Figure 1: flow diagram of a detailed list of inclusion and exclusion criteria). Two patients underwent MSCT despite prior stent implantation. These two patients were included only for AVC analysis. Twenty-one patients had a previous renal transplantation. Median interval between re-initiation of dialysis after transplant failure prior to cardiac MS-CT was 28 months (range $4-63$ months). A subgroup of $40 \mathrm{pa}$ tients from the entire MS-CT cohort were included in a previous publication [6]. In the entire cohort of $67 \mathrm{pa}$ tients, the dominant causes for ESRD were glomerulonephritis or systemic vasculitis in $n=21$ (31\%), ADPKD in $n=9$ (13\%), renal vascular disease or hypertensive nephropathy in $n=11(16 \%)$ and diabetic nephropathy in $n=6(9 \%)$. Arterial hypertension was defined as use of antihypertensive drugs or arterial blood pressure exceeding $130 / 85 \mathrm{mmHg}$.
Table 1 Clinical, demographic, and MSCT data of the entire MSCT cohort $(n=67)$

\begin{tabular}{|c|c|c|}
\hline & & $\begin{array}{l}\text { Entire cohort } \\
(n=67)\end{array}$ \\
\hline Women & {$[n, \%]$} & $35,52 \%$ \\
\hline Median age (range) & [years] & $61(21-87)$ \\
\hline Median BMI (range) & {$\left[\mathrm{kg} / \mathrm{m}^{2}\right]$} & $24(17-53)$ \\
\hline Median time ESRD (range) & [months] & $49(2-364)$ \\
\hline Previous renal transplant & {$[n, \%]$} & $21,31 \%$ \\
\hline Current smoking & {$[n, \%]$} & $10,15 \%$ \\
\hline History of CVD & {$[n, \%]$} & $25,37 \%$ \\
\hline History of CAD & {$[n, \%]$} & $22,33 \%$ \\
\hline Diabetes & {$[n, \%]$} & $15,22 \%$ \\
\hline History of PAD & {$[n, \%]$} & $9,13 \%$ \\
\hline History of Ml & {$[n, \%]$} & $9,13 \%$ \\
\hline History of PTex & {$[n, \%]$} & $9,13 \%$ \\
\hline Median CAC Agatston (range) $(n=65)$ & & $279(0-3736)$ \\
\hline Median Mass CAC (range) $(n=65)$ & & $51(0-643)$ \\
\hline Median Volume CAC (range) $(n=65)$ & & $261(0-3267)$ \\
\hline Median AVC Agatston (range) & & $0(0-1596)$ \\
\hline Median Mass AVC (range) & & $0(0-284)$ \\
\hline Median Volume AVC (range) & & $0(0-1316)$ \\
\hline CAC Agatston score $>100$ & {$[n, \%]$} & $44,66 \%$ \\
\hline Any AVC & {$[n, \%]$} & $27,40 \%$ \\
\hline Usage of Phosphate binders & {$[n, \%]$} & $61,92 \%$ \\
\hline Calcium-based & {$[n, \%]$} & $51,77 \%$ \\
\hline Aluminum-based & {$[n, \%]$} & $14,22 \%$ \\
\hline Calcimimetics & {$[n, \%]$} & $16,25 \%$ \\
\hline
\end{tabular}

Abbreviations: $A V C$ aortic valve calcification; $B M I$ body mass index; $C A C$ coronary artery calcification; $C A D$ coronary artery disease; $C V D$ cerebrovascular disease; ESRD end-stage renal disease; $M I$ myocardial infarction; $M S C T$ multisclice computed tomography; PAD peripheral arterial disease; Ptex parathyroidectomy.

The sclerostin control group consisted of 54 patients from an internal medicine outpatient department $(n=15$ (28\%) males, mean age $57.9 \pm 9.7$ years, eGFR $>60 \mathrm{~mL} /$ min (MDRD formula [17])), whose primary reason for referral was not cardiovascular disease. Those patients were recruited solely based on the absence of overt CKD and not matched to the MSCT cohort in terms of age, sex or underlying extra-renal disease. Within this cohort a broad spectrum of internal medicine diseases was present. Presence or absence of cardiovascular calcification was not systematically evaluated in this cohort, so we on purpose avoid the term "healthy" controls.

We performed ex vivo aortic tissue analyses from overall 15 consecutive long-term HD patients (10 with AVC, 5 without AVC) who did not participate in the MSCT study. Mean age of HD patients with AVC was $56 \pm$ 14 years $(7$ men). Mean age of HD patients with non- 


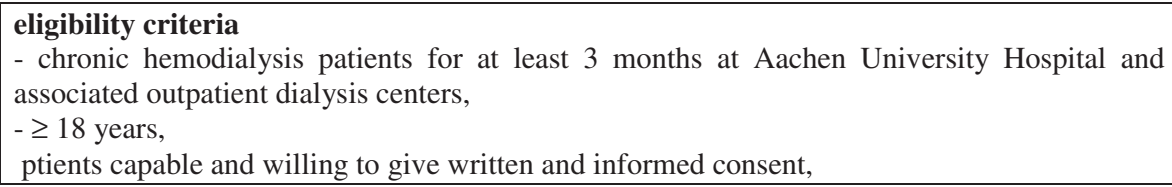

Figure 1 Flow diagram indicating detailed list of eligibility criteria and exclusion criteria of MSCT patients.

calcified aortic valves was $59 \pm 9$ years (three men). Noncalcified aortic valves were identified based on negative routine von Kossa staining. All valves were paraffin embedded prior to IHC staining for sclerostin. The material was retrieved from the Aachen University Pathology Institute biobank after query for "dialysis and aortic valve". Patients with AVC as indicated by positive van Kossa had undergone aortic valve replacement due to severe aortic valve stenosis. The patients without AVC on van Kossa staining had the clinical picture of endocarditis with aortic regurgitation prior to surgery. Based on these selection criteria via the pathology biobank, detailed clinical and laboratory data regarding pre-operative conditions and history were not available in all these patients.

This study was approved by the ethical committee of the RWTH Aachen University Hospital (ethical vote EK 239/11).

\section{$\mathrm{CT}$ imaging procedure}

All MSCT examinations were performed on a 16-slice MSCT scanner (SOMATOM, Sensation 16, Siemens, Forchheim, Germany). Scan parameters included a collimation of $12 \times 0.75 \mathrm{~mm}$, a rotation time of $420 \mathrm{~ms}$, a table feed of $3.4 \mathrm{~mm}$ per rotation, a tube voltage of $120 \mathrm{kV}$ and an effective tube current time product of 150 mAseff. For ECG-synchronization, retrospective ECG gating was applied. Axial images were reconstructed in mid-diastole at $60 \%$ of the RR interval with an effective slice thickness of $3 \mathrm{~mm}$ and a reconstruction increment of $2 \mathrm{~mm}$. A dedicated convolution kernel (B35f), a field of view of $180 \times 180 \mathrm{~mm}^{2}$ and a matrix of $512 \times 512$ were applied. Image analysis was performed on a separate computer workstation (Leonardo, Siemens, Forchheim, Germany) equipped with a dedicated software tool for calcium scoring (Calcium Scoring CT, Siemens, Forchheim, Germany). The CT scans started cranially above the origin of the left main coronary artery and moved caudally to the level of the diaphragm to include all three coronary arteries completely. Complete scanning of the entire aortic arch was not part of the routine protocol. CAC and AVC scores were calculated as the primary read-out according to the method originally described by Agatston et al. [18]. Additionally, the results were expressed as the calcification volume score and mass score automatically provided by the CT-software.

\section{Biochemical analysis}

The parameters serum creatinine (S-creatinine), serum urea, serum phosphorus, total serum calcium $(\mathrm{Ca} 2+)$, haemoglobin $(\mathrm{Hb}), \mathrm{C}$-reactive protein (CRP), alkaline phosphates (AP) and albumin were all measured via standard laboratory methods. We measured total serum calcium without correction for albumin.

For centralized laboratory measurements serum was harvested after an overnight fast after the long dialysis interval prior to dialysis, according to standard procedure, and immediately frozen $\left(-20^{\circ} \mathrm{C}\right)$. Afterwards, samples were transferred to the University Hospital Aachen 
for long-term storage at $-80^{\circ} \mathrm{C}$. The following parameters were all measured centrally after study end: undercarboxylated matrix-Gla protein (ucMGP), fetuin-A, osteoprotegerin (OPG), sclerostin, bone alkaline phosphatase (BAP), and intact parathyroid hormone (iPTH).

UcMGP was measured using a competitive ELISA as previously described by our group [19].

Commercially available ELISA assays were used to determine levels of fetuin-A, OPG, and BAP (TECOmedical AG, Sissach, Switzerland). PTH was measured as intact PTH (iPTH) by an assay provided by Biomerica, USA. Serum sclerostin was assessed by the TECO Sclerostin EIA Kit which is a 96-well immuno-capture ELISA product. Serum samples were incubated with a biotinylated polyclonal antibody as well as with a horseradish peroxidase-labelled secondary monoclonal antibody that specifically recognizes human Sclerostin. Sclerostin molecules are captured on the plate through the binding of streptavidin to the biotinylated primary antibody. After an overnight incubation, the unbound material was washed away. After this washing step, the TMB substrate, which reacts with the HRP, was added to the well and colour was formed. After 15 minutes of incubation, the reaction was stopped with $\mathrm{HCl}$ and the plate was read using a plate reader at $450 \mathrm{~nm}$. The amount of colour generated is directly proportional to the amount of sclerostin in the sample (intratest variability $3.5-5.5 \%)$.

\section{Analysis of sclerostin expression in aortic valves}

After fixation (3.7\% formaldehyde, 24 hours) the valves were paraffin-embedded, cut with a rotating microtome at 3- $\mu \mathrm{m}$ thickness (Leica), and stained according to routine histology protocols. Immunohistochemical analysis was performed using the primary antibody for sclerostin (rabbit polyclonal, 1:200, Santa Cruz Biotechnology, USA, sc-130258). Slide preparations were stained by using an autostainer for immunohistochemistry (DAKO cytomation) with the biotinylated secondary antibody (rabbit/mouse, DAKO), as described previously [20].

Total RNA was isolated from formalin-fixed paraffinembedded aortic valves using RNeasy FFPE Kit (Qiagen, Hilden, Germany). The RNA concentration was determined by measuring absorbance at $260 \mathrm{~nm}$ (Nanodrop, Thermo Scientific, Wilmington, USA). One microgram of RNA was reverse transcribed using the high-capacity cDNA Reverse Transcriptase Kit (Applied Biosystems, Foster City, CA). Quantitative PCR were carried out with Power SYBR Green PCR Master Mix (Applied Biosystems) and the ABI Prism 7300 (Applied Biosystems). The expression of genes of interest was normalized against the housekeeping gene GAPDH. The cDNA of the non-calcified valves from the control patients was used as a relative standard for the sclerostin expression and relative gene expression was analysed with the 2$\Delta \Delta \mathrm{Ct}$ method. The following primers were used: GAPDH Fw 5'-GAAGGTGAAGGTCGGAGTCA-3' Rv 5'-TGGACTCCACGACGTACTCA-3', Sclerostin Fw 5'-CCGGTTCATGGTCTTGTTGTT-3' Rv 5'-ATGCC ACGGAAATCATCCC-3'.

\section{Statistical analysis}

All analyses were done using $\mathrm{SAS}^{\circ}$ statistical software, V9.1.3 (SAS Institute, Cary, NC, USA). Grouping of patients by the Agatston level was used to describe the distribution of serum parameters. We expressed continuous factors as mean values and standard deviation (SD). Categorical factors were presented by frequencies and percentage. To characterize the relation between Agatston level, Pearson correlation coefficients ( $r$ ) were calculated. Unpaired t-tests were used in order to determine differences between groups (e.g. patients with high versus low levels of CVC according to the Agatston level).

In order to investigate the association of various biomarkers with CAC and AVC, we studied all exploratory factors in the first instance in a univariate regression model for continuous factors or in an ANOVA model for categorical factors. Factors which showed a Pvalue $<0.25$ in the univariate analyses were studied simultaneously in a multivariate model (ANCOVA) to explore those factors contributing significant information (P-value falling below the 5\% margin) for predicting the severity of cardiovascular calcification. These analyses were done for the AVC and CAC expressed as Agatston score (primary analysis target), and mass score as well as volume score (secondary analysis targets). Regarding $\mathrm{CAC}$ the multivariate analyses were repeated after log transformation of CAC levels in those patients with CAC baseline levels greater than zero $(n=61)$. Log transformation was not performed regarding AVC levels because of the high proportion of patients without AVC calcification.

Student's $t$-test was used for statistical analysis of sclerostin mRNA expression.

All test results are reported as $\mathrm{P}$-values (P), estimates and corresponding $95 \%$ limits of confidence.

\section{Results}

\section{Serum sclerostin in patients}

In 54 controls serum sclerostin levels were significantly lower than in HD patients [0.76 \pm 0.31 vs $1.53 \pm 0.81 \mathrm{ng} /$ $\mathrm{mL}(\mathrm{p}<0.00019)]$. The median $\left(25^{\text {th }}\right.$ to $75^{\text {th }}$ percentile $)$ levels of sclerostin were 0.69 (0.58 to 0.89$) \mathrm{ng} / \mathrm{mL}$ in controls and 1.44 (0.95 to 2.01$) \mathrm{ng} / \mathrm{mL}$ in patients. In controls the distribution of sclerostin levels was as follows: $14 \%$ revealed serum sclerostin $<0.50 \mathrm{ng} / \mathrm{mL}, 72 \%$ between 0.51 to $1.00 \mathrm{ng} / \mathrm{mL}$, and $14 \%>1.01 \mathrm{ng} / \mathrm{mL}$. In hemodialysis patients the distribution was broader and 
right-shifted with levels $<0.50 \mathrm{ng} / \mathrm{mL}$ in $7 \%, 0.51$ to $1.00 \mathrm{ng} / \mathrm{mL}$ in $14 \%, 1.01$ to $1.50 \mathrm{ng} / \mathrm{mL}$ in $32 \%, 1.51$ to $2.00 \mathrm{ng} / \mathrm{mL}$ in $19 \%, 2.01$ to $2.50 \mathrm{ng} / \mathrm{mL}$ in $14 \%$ and > $2.51 \mathrm{ng} / \mathrm{mL}$ in $14 \%$, respectively.

\section{Distribution of calcification levels for CAC and AVC}

There were only 6 patients (9\%) without CAC and 40 patients (60\%) without detectable AVC. The mean Agatston CAC score was $647 \pm 854$ (range $0-3736$ ). 23 patients had CAC levels below 100 (35\%) and 29 (45\%) showed CAC scores exceeding 400. The mean CAC mass and volume score were $118 \pm 155$ and $572 \pm 720$, respectively. The mean level of AVC was $76 \pm 233$ (range 0 - 1596, Agatston score) at baseline. Twelve patients (18\%) showed AVC Agatston score $>100$. The mean AVC mass score was $13 \pm 41$ and the AVC volume score was $64 \pm 194$.

\section{Association between CAC and AVC}

There was a statistically significant correlation between CAC and AVC $(r=0.34, p=0.0055)$. For patients with CAC exceeding 100, the AVC Agatston score was not significantly different from patients with CAC below 100 $(104 \pm 288$ vs $14 \pm 35, p=0.143)$. Accordingly, patients positive for AVC at baseline did not have significantly different CAC scores $(870 \pm 915$ vs $507 \pm 794$ for patients with no AV; $\mathrm{p}=0.095)$.

\section{Intergroup comparison between patients with different levels of calcification}

After stratifying the patients for $\mathrm{CAC}<100$ versus $>100$, the group with CAC levels exceeding 100 revealed significantly higher levels of OPG: $5.95 \pm 2.53$ vs $4.13 \pm 2.62$ $\mathrm{pmol} / \mathrm{L}(\mathrm{P}=0.0133)$. These severely calcified patients were also significantly older $(64 \pm 12$ vs $51 \pm 16$ years; $\mathrm{P}=0.0003$ ) (Table 2). None of the other parameters listed in Table 2 were significantly different between the two CAC groups. Patients with CAC Agatston score > 400 revealed OPG levels of $5.81 \pm 2.67$ (compared to $4.13 \pm 2.62 \mathrm{pmol} / \mathrm{L}, \mathrm{p}=0.02$ ). After stratifying patients according to presence or absence of AVC, the intergroup comparison revealed significantly lower sclerostin levels in patients without AVC $(1.35 \pm 0.73$ vs $1.78 \pm 0.84 \mathrm{ng} /$ $\mathrm{mL} ; \mathrm{P}=0.0311)$. There were no additional parameters with significant differences between the two AVC groups (Table 3).

\section{Association between sclerostin and cardiovascular calcification}

For both CAC and AVC, univariate and multivariate regression analyses were performed.

Depending on the P-values obtained in the univariate analysis ( $\mathrm{P} \leq 0.25$ in Table 4 ), age, male sex, BMI, diabetes, OPG, IPTH, and ucMGP were included in the
Table 2 Intergroup comparison for dialysis patients according to CAC level at baseline $(n=65)$

\begin{tabular}{llll}
\hline & & CAC $<\mathbf{1 0 0}$ & CAC >100 (65\%) \\
\hline$N$ & {$[\mathrm{n},(\%)]$} & $23(35 \%)$ & $42(65 \%)$ \\
Gender (male) & {$[\mathrm{n},(\%)]$} & $10(45 \%)$ & $21(50 \%)$ \\
Age & {$[\mathrm{yrs}]$} & $51 \pm 16$ & $64 \pm 12$ \\
Time since first dialysis $[\mathrm{mo}]$ & & $87 \pm 88$ & $64 \pm 68$ \\
BMl & {$\left[\mathrm{kg} / \mathrm{m}^{2}\right]$} & $26 \pm 7$ & $25 \pm 5$ \\
CAC Agatston & $28 \pm 35$ & $1014 \pm 907$ & \\
AVC Agatson & $14 \pm 35$ & $88 \pm 266$ & \\
ucMGP & {$[\mathrm{nmol} / \mathrm{L}]$} & $2199 \pm 714$ & $2423 \pm 725$ \\
Fetuin-A & {$[\mathrm{g} / \mathrm{L}]$} & $0.47 \pm 0.12$ & $0.45 \pm 0.08$ \\
OPG & {$[\mathrm{pmol} / \mathrm{L}]$} & $4.13 \pm 2.62$ & $5.95 \pm 2.53$ \\
Sclerostin & {$[\mathrm{ng} / \mathrm{mL}]$} & $1.52 \pm 0.71$ & $1.54 \pm 0.86$ \\
CRP & {$[\mathrm{mg} / \mathrm{L}]$} & $4.19 \pm 6.35$ & $8.05 \pm 6.67$ \\
iPTH & {$[\mathrm{pg} / \mathrm{mL}]$} & $119 \pm 139$ & $282 \pm 396$ \\
BAP & {$[\mathrm{U} / \mathrm{L}]$} & $29 \pm 22$ & $33 \pm 28$ \\
AP & {$[\mathrm{U} / \mathrm{L}]$} & $82 \pm 46$ & $89 \pm 72$ \\
Total Ca2+ & {$[\mathrm{mmol} / \mathrm{L}]$} & $2.25 \pm 0.27$ & $2.39 \pm 0.29$ \\
Phosphorus & {$[\mathrm{mmol} / \mathrm{L}]$} & $1.77 \pm 0.53$ & $1.83 \pm 0.50$ \\
Albumin & {$[\mathrm{g} / \mathrm{L}]$} & $39 \pm 8$ & $39 \pm 4$ \\
Haemoglobin & {$[\mathrm{g} / \mathrm{L}]$} & $109 \pm 14$ & $109 \pm 27$ \\
S-Creatinine & {$[\mathrm{mg} / \mathrm{dL}]$} & $9.7 \pm 3.2$ & $9.1 \pm 2.6$ \\
S-Urea & {$[\mathrm{mmol} / \mathrm{L}]$} & $82 \pm 60$ & $62 \pm 61$ \\
\hline
\end{tabular}

multivariable analysis for CAC. This multivariable analysis revealed that the presence of diabetes was significantly associated with CAC levels (Table 5, Agatston score). Similar results regarding the association with diabetes were obtained when analysing the volume CAC score and the mass CAC score (data not shown). The same model in $n=61$ patients was applied after $\log$ transformation of CAC levels with age, male sex, BMI, calcium, OPG, CRP, and ucMGP entering the multivariate analysis. None of these univariate associations with $\log$ transformed CAC remained statistically significant after multivariate analysis.

Regarding AVC (Agatston score) the univariate analysis (Table 6) resulted in inclusion of age, male sex, diabetes and serum sclerostin to the multivariable analysis. There was a significant association between serum sclerostin and the extent of AVC at baseline $(P=0.0170)$ (Table 7). Similar results regarding the association of serum sclerostin and AVC were obtained when anaylsing the volume AVC score and the mass AVC score (data not shown).

\section{Sclerostin expression in aortic valves}

Immunohistochemical staining for sclerostin revealed sclerostin expression in all of the 10 calcified aortic 
Table 3 Intergroup comparison for dialysis patients according to AVC level at baseline $(n=67)$

\begin{tabular}{|c|c|c|c|}
\hline & & No AVC & Present AVC \\
\hline $\mathrm{N}$ & {$[n ; \%]$} & $40 ; 60 \%$ & $27 ; 40 \%$ \\
\hline Gender (male) & {$[n ; \%]$} & $19 ; 48 \%$ & $13 ; 48 \%$ \\
\hline Age & [yrs] & $57 \pm 16$ & $63 \pm 13$ \\
\hline Time since first dialysis [mo] & & $76 \pm 85$ & $79 \pm 81$ \\
\hline BMI & {$\left[\mathrm{kg} / \mathrm{m}^{2}\right]$} & $25 \pm 5$ & $26 \pm 7$ \\
\hline CAC Agatston & & $507 \pm 794$ & $918 \pm 938$ \\
\hline AVC Agatson & & $0 \pm 0$ & $189 \pm 340$ \\
\hline ucMGP & {$[\mathrm{nmol} / \mathrm{L}]$} & $2366 \pm 791$ & $2261 \pm 589$ \\
\hline Fetuin-A & {$[g / L]$} & $0.46 \pm 0.11$ & $0.46 \pm 0.07$ \\
\hline OPG & {$[p m o l / L]$} & $4.96 \pm 2.60$ & $5.63 \pm 2.819$ \\
\hline Sclerostin & {$[\mathrm{ng} / \mathrm{mL}]$} & $1.35 \pm 0.73$ & $1.78 \pm 0.84$ \\
\hline CRP & {$[\mathrm{mg} / \mathrm{L}]$} & $7.77 \pm 7.78$ & $5.65 \pm 4.55$ \\
\hline iPTH & {$[\mathrm{pg} / \mathrm{mL}]$} & $242 \pm 350$ & $190 \pm 301$ \\
\hline BAP & {$[\mathrm{U} / \mathrm{L}]$} & $36 \pm 30$ & $27 \pm 18$ \\
\hline AP & {$[\mathrm{U} / \mathrm{L}]$} & $91 \pm 60$ & $79 \pm 66$ \\
\hline Total Ca2+ & {$[\mathrm{mmol} / \mathrm{L}]$} & $2.39 \pm 0.21$ & $2.27 \pm 0.36$ \\
\hline Phosphorus & {$[\mathrm{mmol} / \mathrm{L}]$} & $1.76 \pm 0.47$ & $1.95 \pm 0.63$ \\
\hline Albumin & {$[g / L]$} & $39 \pm 7$ & $39 \pm 4$ \\
\hline $\mathrm{Hb}$ & {$[\mathrm{g} / \mathrm{L}]$} & $111 \pm 14$ & $108 \pm 32$ \\
\hline S-Creatinine & {$[\mathrm{mg} / \mathrm{dL}]$} & $9.2 \pm 2.9$ & $9.8 \pm 3.0$ \\
\hline S-Urea & {$[\mathrm{mmol} / \mathrm{L}]$} & $65 \pm 59$ & $81 \pm 63$ \\
\hline
\end{tabular}

valves while there was no sclerostin expression in the non-calcified control valves (Figure 2). The immunohistochemistry showed a strong sclerostin expression very close to the calcified regions (Figure 2B-i) but also a faint sclerostin expression in the non-calcified regions of the calcified valves from all of the haemodialysis patients (Figure $2 \mathrm{C}$-i). In contrast, we did not observe any sclerostin expression in the non-calcified valves (Figure 2B-ii and $\mathrm{C}$-ii). This finding was confirmed on the mRNA level via Qt-RT-PCR as we observed a highly significant upregulation of sclerostin mRNA in the calcified aortic valves of haemodialysis patients compared to non-calcified control valves $(\mathrm{P}<0.001)$ (Figure $2 \mathrm{D})$.

\section{Discussion}

The major findings of the present study were that in dialysis patients high serum sclerostin was associated with the extent of AVC and that in aortic valve tissue, sclerostin strongly co-localized with areas of calcification. In the last decade, numerous studies have investigated cardiovascular calcifications in adult haemodialysis patients (e.g. [6,21-23]). CVC clearly influences outcome in ESRD patient since previous studies could show an independent influence of baseline CVC [24] and its progression [2] upon mortality in these patients.
Table 4 Univariate associate factor analysis regarding CAC Agatston score at baseline

\begin{tabular}{lllll}
\hline & & \multicolumn{2}{l}{$\mathbf{9 5 \%}$ limits of confidence } & \\
\cline { 3 - 4 } Parameter & Estimate & Lower & Upper & p-value \\
\hline Age & 8.7 & -5.9 & 23 & 0.23 \\
Gender male & 411 & -2.5 & 826 & 0.0358 \\
Non-Smoking & -179 & -800 & 442 & 0.3364 \\
Non-Diabetics & -1145 & -1661 & -628 & 0.0012 \\
Time ESRD & -0.6 & -3.3 & 2.4 & 0.67 \\
BMI & -25 & -64 & 11 & 0.20 \\
Fetuin-A & -38 & -2306 & 14 & 0.97 \\
Total Ca2+ & 55 & -741 & 762 & 0.89 \\
OPG & 62 & -13 & 141 & 0.13 \\
CRP & 4.6 & -33 & 44 & 0.81 \\
Sclerostin & 77 & -190 & 340 & 0.57 \\
iPTH & 0.3 & -0.2 & 3.1 & 0.25 \\
Pho4+ & 83 & -329 & 458 & 0.70 \\
ucMGP & 0.4 & 0.1 & 0.7 & 0.0160 \\
BAP & 0.44 & -7.0 & 8.0 & 0.91 \\
Albumin & -7.5 & -44 & 21 & 0.66 \\
\hline
\end{tabular}

Calcification of the aortic valves is an important part of the uraemic calcification syndrome. It has been previously shown that in patients without advanced renal failure there is a significant correlation between the amount of aortic valve calcification and the degree of aortic valve stenosis [25].

Previously published studies in dialysis patients regarding the association between various biochemical parameters and the degree of cardiovascular calcification do not show a homogeneous picture: Numerous circulating factors have been elaborated on so far as being associated with CAC or AVC but other studies failed to confirm these associations $[1,6,22,26]$. For example, the present study does not confirm an independent association between low levels of serum fetuin-A or high levels of OPG with CAC in contrast to a previous study by Moe et al. [12]. Our present data also differ from

Table 5 Multivariate associate factor analysis regarding CAC Agatston score at baseline

\begin{tabular}{lllll}
\hline Parameter & Estimate & Lower & Upper & p-value \\
\hline OPG & 46.62 & -70 & 96 & 0.33 \\
iPTH & 0.42 & -0.04 & 1.1 & 0.16 \\
uCMGP & 0.21 & -0.1 & 0.5 & 0.16 \\
Age & 4.72 & -236 & 2459 & 0.56 \\
Gender male & 267 & -90 & 624 & 0.054 \\
BMl & -22 & -54 & 7.6 & 0.23 \\
Non-diabetics & -1118 & -1696 & -540 & 0.0019 \\
\hline
\end{tabular}


Table 6 Univariate associate factor analysis regarding AVC Agatston score at baseline

\begin{tabular}{lllll}
\hline & & \multicolumn{2}{l}{$\mathbf{9 5 \%}$ limits of confidence } & \\
\cline { 3 - 4 } Parameter & Estimate & Lower & Upper & p-value \\
\hline Age & 3.4 & -0.4 & 7.4 & 0.08 \\
Gender male & 100 & -15 & 215 & 0.098 \\
Non-Smoking & -48 & -220 & 123 & 0.54 \\
Non-diabetics & -121 & -281 & 39 & 0.0560 \\
ime ESRD & -0.07 & -1.0 & 0.6 & 0.84 \\
BMI & 1.29 & -8.8 & 12 & 0.81 \\
Fetuin-A & -29 & -678 & 618 & 0.93 \\
Total Ca2+ & -75 & -282 & 130 & 0.46 \\
OPG & 12 & -9.5 & 36 & 0.27 \\
CRP & -1.3 & -12 & 9.5 & 0.81 \\
Sclerostin & 102 & 35 & 179 & 0.0058 \\
iPTH & -0.04 & -0.2 & 0.2 & 0.71 \\
Pho4+ & -50 & -61 & 155 & 0.35 \\
uCMGP & 0.24 & -0.1 & 0.1 & 0.56 \\
BAP & -0.8 & -3.5 & 1.4 & 0.51 \\
Albumin & -2.7 & -15 & 8.5 & 0.63 \\
\hline
\end{tabular}

previous results that indicated a link between ucMGP levels and CAC in a smaller cohort of HD patients [27]. We can only speculate about the potential reasons. The different methodology of calcification detection and cohort size may play a role. Similarly, different patient characteristics (ethnic background, proportion of diabetics, dialysis vintage etc.) and moreover, preanalytical biomarker stability and assay characteristics of the investigated biomarkers clearly influence such associative investigations. In that respect it is noteworthy that especially fetuin-A serum measurements reveal meaningful differences depending on analytical procedures [28] and that previous data from our group indicating a link between fetuin-A in serum and the magnitude of $\mathrm{VC}$ had not been obtained by the TECOmedical assay used in the present study. So differences in serum fetuin-A assay set-ups most likely contribute to inconsistencies in terms of associations with the degree of calcification [12]. Similarly we need to point out that also previously reported serum sclerostin levels vary largely with different assays in hemodialysis patients: Data from

Table 7 Multivariate associate factor analysis regarding AVC Agatston score at baseline

\begin{tabular}{lllll}
\hline Parameter & Estimate & Lower & Upper & p-value \\
\hline Sclerostin & 91 & 4.1 & 150 & 0.0170 \\
Age & 2.21 & -1.0 & 7.2 & 0.28 \\
Non-diabetics & -86 & -250 & 79 & 0.08 \\
Gender male & 99 & -20 & 217 & 0.15 \\
\hline
\end{tabular}

our lab show a $45 \%$ lower circulating sclerostin concentration in hemodialysis patients measured with the TECOmedical assay compared to the Biomedica assay (V. Brandenburg, unpublished data).

Despite these limitations regarding biomarkers in uremic cardiovascular disease we see a convincing rationale to introduce sclerostin in CKD-mineral and bone disorder. Sclerostin strongly regulates bone metabolism. Genetically engineered animal models prove the role of sclerostin as a bone-suppressive factor [29,30]. Sclerostin knock-out mice were characterized by increased bone density and strength. Sclerostin exerts its osteo-suppressive actions via interference with the Wnt -signalling pathway [31]. The regulation of the Wnt-signalling pathway may contribute locally and/or systemically to bone and mineral disorders in CKD [15,32]. Recent study findings indicate that sclerostin is also involved in vascular disease. An in vitro and rodent study by Zhu et al. could show that sclerostin is upregulated in experimental models of vascular calcification [33]. We extend these findings for the first time to a potential linkage between sclerostin levels and AVC in humans with ESRD. The present data are in line with recent human study results indicating an association of sclerostin expression with non-uremic aortic valve calcification [34]. Therefore, sclerostin appears to be a promising future research target in CKD-MBD offering potential therapeutic perspectives $[29,35]$.

Our data upon sclerostin expression in the vascular system stimulate the discussion about osteocyte involvement in vascular and valvular calcification processes. As previously speculated by Zhu et al. [33] the occurrence of sclerostin in the vasculature may indicate a terminal transdifferentiation from VSMCs towards a mature, osteocyte-like cell type. Zhu and coworkers investigated various osteocyte markers (e.g. DMP-1 and sclerostin) in different in vitro and in vivo calcification models. Indeed, VSMC sclerostin expression was stimulated by incubation in pro-calcific media and accordingly, sclerostin was detected in calcified aortas from ectonucleotide pyro phosphatase/phosphodiesterase 1 null mice [33]. Moreover, the different temporal course of osteocytic marker expression in osteoblasts compared to VSMC indicates that stimulated osteoblasts undergo this maturation process more readily than VSMC [33]. At that point, a crucial question arises whether local sclerostin production and systemic levels play a causal role in, or even trigger, the development CVC. Alternatively, sclerostin occurrence may just reflect a general phenotypic change of the vascular wall cells towards a bone-like phenotype. Most importantly, however, future longitudinal studies need to address the question whether sclerostin overexpression might even be vasculoprotective and anti-calcific via e.g. its indirect BMP-2 antagonistic activities. 


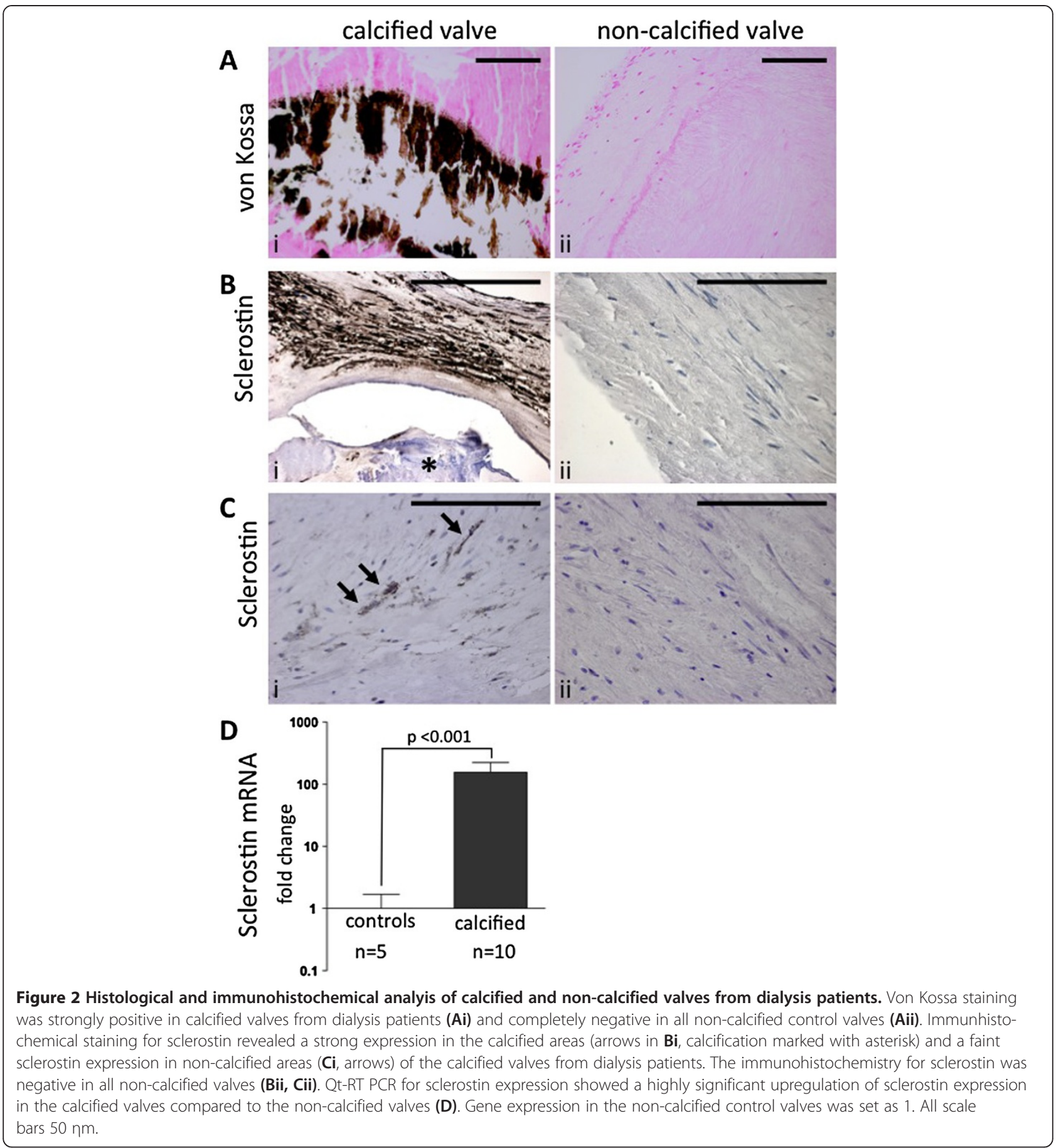

It remains unclear why there was apparently no association between the amount of CAC and serum sclerostin levels. It is also unclear if the increase of serum sclerostin may be due to increased skeletal or extraosseous production, due to diminished renal clearance or both. The trial design does not allow drawing reliable conclusions of how CKD-MBD therapy (dialysis procedure, co-medication) influences sclerostin levels. At present, the biological meaning of the serum sclerostin differences between patients with AVC versus those without remains speculative. In conjunction with a recent publication by our group [34] serum sclerostin levels as measured with the present ELISA gradually increase with increasing cardiovascular disease burden: from controls without overt cardiovascular disease $(0.76 \pm 0.31 \mathrm{ng} / \mathrm{mL})$, via non-renal patients with AVC $(0.94 \pm 0.45 \mathrm{ng} / \mathrm{mL}$ [34] $)$, and via dialysis patients without AVC $(1.35 \pm 0.73 \mathrm{ng} / \mathrm{mL})$ finally to dialysis patients 
with AVC $(1.78 \pm 0.84 \mathrm{ng} / \mathrm{mL})$. Overall, we are aware that defining the exact association between serum sclerostin and CKD-MBD is challenging, and future human sclerostin studies in CKD-MBD should incorporate both vascular and osseous assessment [36,37]. The present data do not allow drawing firm conclusions whether sclerostin is within the aetiological pathway of uremic AVC development and whether baseline sclerostin levels are a risk factor for future CVC development.

We acknowledge several additional limitations of the present study including the cross-sectional nature, the small sample size of the MSCT patient group, the limited ability to adjust for all potential confounders as well as limited data availability in terms of treatment and comorbidities regarding the patients with aortic valve replacement. Moreover, we used only one assay type per parameter limiting the ability to universalize the associative data between biomarker with vascular calcification.

\section{Conclusion}

In summary, we identified an association between both tissue sclerostin as well as serum sclerostin with aortic valve calcification in haemodialysis patients. Strength of our data is the homology between ex vivo (IHC) and in vivo (MS-CT) data. These findings add novel aspects to the well-described link between bone metabolism and cardiovascular health (bone-vascular axis) in uraemia. Further studies need to address the cellular origin of local sclerostin production and also investigate whether the appearance of sclerostin aggravates or rather slows down cardiovascular calcification processes.

\begin{abstract}
Abbreviations
ADPKD: Autosomal dominant polycystic kidney disease; (B)AP: (Bone) alkaline phosphatase; AVC: Aortic valve calcification; CAC: Coronary artery calcification; CKD: Chronic kidney disease; CKD-MBD: Chronic kidney disease - bone and mineral disorder; CRP: C-reactive protein; CVC: Cardiovascular calcification; ECG: Electrocardiogram; ELISA: Enzyme-linked immunosorbent assay; ESRD: End-stage renal disease; IHC: Immunohistochemistry; Hb: Haemoglobin; HD: Hemodialysis; (uc)MGP: (Uncarboxylated) matrix-gla protein; MS-CT: Multislice computed tomography; OPG: Osteoprotegerin; (i)PTH: (Intact) parathyroid hormone; Qt-RT-PCR: Quantitative reverse transcription polymerase chain reaction; RNA: Ribonucleic acid; SD: Standard deviation; VC: Vascular calcification.
\end{abstract}

\section{Competing interests}

The authors declared that they have no competing interests.

\footnotetext{
Authors' contributions

VMB participated in developing the study design and conception of the study, recruitment of patients, performing the study and acquisition of data, laboratory analysis, immunohistochemistry, statistical analyses, and drafted the manuscript. VMB also revised the manuscript critically of intellectual content. RK participated in developing the study design and conception of the study, recruitment of patients, performing the study and acquisition of data, laboratory analysis, immunohistochemistry, statistical analyses, and drafted the manuscript. RK also revised the manuscript critically of intellectual content. RK participated in laboratory analysis, immunohistochemistry, statistical analyses, and drafted the manuscript. TK participated in laboratory analysis, immunohistochemistry, statistical analyses, and drafted the manuscript. LS participated in immunohistochemistry, statistical analyses, and drafted the manuscript. GM was responsible for
}

performance of computed tomography calcification measurement, quality control and analyses. SH participated in recruitment of patients, performing the study and acquisition of data, laboratory analysis and drafted the manuscript. UG participated in recruitment of patients, performing the study and acquisition of data, laboratory analysis and drafted the manuscript. CD participated in statistical analyses, and drafted the manuscript. MK participated in developing the study design and conception of the study, recruitment of patients, performing the study and acquisition of data, laboratory analysis, immunohistochemistry, statistical analyses, and drafted the manuscript. MK also revised the manuscript critically of intellectual content. All authors read and approved the final manuscript.

\section{Acknowledgements}

Data were presented in part as abstract at the ASN renal week congress 2010.

\section{Author details}

'Department of Cardiology, University Hospital of the RWTH, Pauwelsstraße 30, D- 52057 Aachen, Germany. Department of Nephrology, University Hospital of the RWTH Aachen, Aachen, Germany. ${ }^{3}$ Department of Biochemistry, Cardiovascular Research Institute Maastricht (CARIM), Maastricht University, Maastricht, the Netherlands. ${ }^{4}$ Department of Neuro-Radiology, University Hospital of the RWTH Aachen, Aachen, Germany. ${ }^{5}$ Dialysis Center, Kuratorium für Heimdialyse, Würselen, Germany. ${ }^{6}$ Department of Internal Medicine 1, Division of Nephrology, University of Würzburg, Würzburg, Germany. 'Department of Nephrology, Klinikum Coburg, Coburg, Germany.

Received: 3 June 2013 Accepted: 1 October 2013

Published: 10 October 2013

\section{References}

1. Coen G, Pierantozzi A, Spizzichino D, Sardella D, Mantella D, Manni M, et al: Risk factors of one year increment of coronary calcifications and survival in hemodialysis patients. BMC Nephrol 2010, 11:10.

2. Noordzij M, Cranenburg EM, Engelsman LF, Hermans MM, Boeschoten EW, Brandenburg VM, et al: Progression of aortic calcification is associated with disorders of mineral metabolism and mortality in chronic dialysis patients. Nephrol Dial Transplant 2010, 26:1662-1669.

3. Ohtake T, Ishioka K, Honda K, Oka M, Maesato K, Mano T, et al: Impact of coronary artery calcification in hemodialysis patients: risk factors and associations with prognosis. Hemodial Int 2010, 14:218-225.

4. Shantouf RS, Budoff MJ, Ahmadi N, Ghaffari A, Flores F, Gopal A, et al: Total and individual coronary artery calcium scores as independent predictors of mortality in hemodialysis patients. Am J Nephrol 2010, 31:419-425.

5. Kurnatowska I, Grzelak P, Kaczmarska M, Stefanczyk L, Nowicki M: Serum osteoprotegerin is a predictor of progression of atherosclerosis and coronary calcification in hemodialysis patients. Nephron Clin Pract 2010, 117:c297-c304.

6. Cranenburg EC, Brandenburg VM, Vermeer C, Stenger M, Muhlenbruch G, Mahnken AH, et al: Uncarboxylated matrix Gla protein (ucMGP) is associated with coronary artery calcification in haemodialysis patients. Thromb Haemost 2009, 101:359-366.

7. Barreto DV, Barreto FC, Carvalho AB, Cuppari L, Draibe SA, Dalboni MA, et al: Association of changes in bone remodeling and coronary calcification in hemodialysis patients: a prospective study. Am J Kidney Dis 2008, 52:1139-1150.

8. Kirkpantur A, Altun B, Hazirolan T, Akata D, Arici M, Kirazli S, et al: Association among serum fetuin-A level, coronary artery calcification, and bone mineral densitometry in maintenance hemodialysis patients. Artif Organs 2009, 33:844-854.

9. Hermans MM, Brandenburg V, Ketteler M, Kooman JP, van der Sande FM, Boeschoten EW, et al: Association of serum fetuin-A levels with mortality in dialysis patients. Kidney Int 2007, 72:202-207.

10. Morena M, Terrier N, Jaussent I, Leray-Moragues H, Chalabi L, Rivory JP, et al: Plasma osteoprotegerin is associated with mortality in hemodialysis patients. J Am Soc Nephrol 2006, 17:262-270.

11. Regidor DL, Kovesdy CP, Mehrotra R, Rambod M, Jing J, McAllister CJ, et al: Serum alkaline phosphatase predicts mortality among maintenance hemodialysis patients. J Am Soc Nephrol 2008, 19:2193-2203.

12. Moe SM, Reslerova M, Ketteler M, O'neill K, Duan D, Koczman J, et al: Role of calcification inhibitors in the pathogenesis of vascular calcification in chronic kidney disease (CKD). Kidney Int 2005, 67:2295-2304. 
13. Moester MJ, Papapoulos SE, Lowik CW, van Bezooijen RL: Sclerostin: current knowledge and future perspectives. Calcif Tissue Int 2010, 87:99-107.

14. Kubota T, Michigami T, Ozono K: Wnt signaling in bone metabolism. $J$ Bone Miner Metab 2009, 27:265-271.

15. Brandenburg V, Lehmann G, Schuetze J, Wolf G: Novel markers for renal osteodystrophy (ROD). J Am Soc Nephrol ASN renal week 2010 (Abstract).

16. Cejka D, Herberth J, Branscum AJ, Fardo DW, Monier-Faugere MC, Diarra D, et al: Sclerostin and Dickkopf-1 in renal osteodystrophy. Clin J Am SoC Nephrol 2011, 6:877-82.

17. Levey AS, Bosch JP, Lewis JB, Greene T, Rogers N, Roth D: A more accurate method to estimate glomerular filtration rate from serum creatinine: a new prediction equation. Modification of Diet in Renal Disease Study Group. Ann Intern Med 1999, 130:461-470.

18. Agatston AS, Janowitz WR, Hildner FJ, Zusmer NR, Viamonte M Jr, Detrano R: Quantification of coronary artery calcium using ultrafast computed tomography. J Am Coll Cardiol 1990, 15:827-832.

19. Cranenburg EC, Koos R, Schurgers LJ, Magdeleyns EJ, Schoonbrood TH, Landewe RB, et al: Characterisation and potential diagnostic value of circulating matrix Gla protein (MGP) species. Thromb Haemost 2010, 104:811-822.

20. Kramann R, Couson SK, Neuss S, Kunter U, Bovi M, Bornemann J, et al: Exposure to uremic serum induces a procalcific phenotype in human mesenchymal stem cells. Arterioscler Thromb Vasc Biol 2011, 31:e45-e54.

21. Bellasi A, Ferramosca E, Muntner P, Ratti C, Wildman RP, Block GA, et al: Correlation of simple imaging tests and coronary artery calcium measured by computed tomography in hemodialysis patients. Kidney Int 2006, 70:1623-1628.

22. Barreto DV, Barreto FC, Carvalho AB, Cuppari L, Cendoroglo M, Draibe SA, et al: Coronary calcification in hemodialysis patients: the contribution of traditional and uremia-related risk factors. Kidney Int 2005, 67:1576-1582.

23. Block GA, Spiegel DM, Ehrlich J, Mehta R, Lindbergh J, Dreisbach A, et al: Effects of sevelamer and calcium on coronary artery calcification in patients new to hemodialysis. Kidney Int 2005, 68:1815-1824.

24. Matsuoka M, Iseki K, Tamashiro M, Fujimoto N, Higa N, Touma T, et al: Impact of high coronary artery calcification score (CACS) on survival in patients on chronic hemodialysis. Clin Exp Nephrol 2004, 8:54-58.

25. Koos R, Mahnken AH, Sinha AM, Wildberger JE, Hoffmann R, Kuhl HP: Aortic valve calcification as a marker for aortic stenosis severity: assessment on 16-MDCT. AJR Am J Roentgenol 2004, 183:1813-1818.

26. Jung HH, Kim SW, Han H: Inflammation, mineral metabolism and progressive coronary artery calcification in patients on haemodialysis. Nephrol Dial Transplant 2006, 21:1915-1920.

27. Cranenburg EC, Vermeer C, Koos R, Boumans ML, Hackeng TM, Bouwman $\mathrm{FG}$, et al: The circulating inactive form of matrix Gla Protein (ucMGP) as a biomarker for cardiovascular calcification. J Vasc Res 2008, 45:427-436.

28. Smith ER, Holt SG: Important differences in measurement of fetuin-A. Ann Intern Med 2010, 153:419-420.

29. Li X, Ominsky MS, Niu QT, Sun N, Daugherty B, D'Agostin D, et al: Targeted deletion of the sclerostin gene in mice results in increased bone formation and bone strength. J Bone Miner Res 2008, 23:860-869.

30. Winkler DG, Sutherland MK, Geoghegan JC, Yu C, Hayes T, Skonier JE, et al: Osteocyte control of bone formation via sclerostin, a novel BMP antagonist. EMBO J 2003, 22:6267-6276.

31. Krause C, Korchynskyi O, de Rooij K, Weidauer SE, de Gorter DJ, van Bezooijen RL, et al: Distinct modes of inhibition by sclerostin on bone morphogenetic protein and Wnt signaling pathways. J Biol Chem 2010, 285:41614-41626.

32. Cejka D, Herberth J, Branscum AJ, Fardo DW, Monier-Faugere MC, Diarra D, et al: Sclerostin and Dickkopf-1 in renal osteodystrophy. Clin J Am SoC Nephrol 2010, 6:8877-8882.

33. Zhu D, Mackenzie NC, Millan JL, Farquharson C, MacRae VE: The appearance and modulation of osteocyte marker expression during calcification of vascular smooth muscle cells. PLoS One 2011, 6:e19595.

34. Koos R, Brandenburg V, Mahnken AH, Schneider RK, Dohmen G, Autschbach R, et al: Sclerostin as potential novel biomarker for artic valve calcification: an in vivo and ex vivo study. J Heart Valv Dis 2013, 22:317-26.

35. Ke HZ, Richards WG, Li X, Ominsky MS: Sclerostin and Dickkopf-1 as therapeutic targets in bone diseases. Endocr Rev 2012, 33:747-83.
36. Cejka D, Jager-Lansky A, Kieweg H, Weber M, Bieglmayer C, Haider DG, et al: Sclerostin serum levels correlate positively with bone mineral density and microarchitecture in haemodialysis patients. Nephrol Dial Transplant 2012, 27:226-230

37. Thambiah S, Roplekar R, Manghat P, Fogelman I, Fraser WD, Goldsmith D, et al: Circulating sclerostin and Dickkopf-1 (DKK1) in predialysis chronic kidney disease (CKD): relationship with bone density and arterial stiffness. Calcif Tissue Int 2012, 90:473-480.

doi:10.1186/1471-2369-14-219

Cite this article as: Brandenburg et al:: Relationship between sclerostin and cardiovascular calcification in hemodialysis patients: a crosssectional study. BMC Nephrology 2013 14:219.

\section{Submit your next manuscript to BioMed Central and take full advantage of:}

- Convenient online submission

- Thorough peer review

- No space constraints or color figure charges

- Immediate publication on acceptance

- Inclusion in PubMed, CAS, Scopus and Google Scholar

- Research which is freely available for redistribution 